\section{Estudo \\ CoDebate}

em CAStão

Plamejamento
Revista Estudo \& Debate, Lajeado, v. 24, n. 3, 2017. ISSN 1983-036X

DOI: http://dx.doi.org/10.22410/issn.1983-036X.v24i3a2017.1196

\title{
OS EMPREENDIMENTOS DE FEIRAS LIVRES DO MUNICÍPIO DE SANTA MARIA/RS - CARACTERIZAÇÁO E SUSTENTABILIDADE
}

\author{
Andrea da Silva ${ }^{1}$, Claus Haetinger ${ }^{2}$
}

\begin{abstract}
Resumo: As feiras livres têm uma grande importância para a comunidade local, ao homem do campo e à agricultura familiar, pois se apresentam como um caminho de desenvolvimento e fortalecimento da cadeia produtiva. O presente artigo busca caracterizar os empreendimentos de feiras livres do município de Santa Maria/RS, e averiguar sua sustentabilidade sob os aspectos - social, econômico e ambiental. Os procedimentos metodológicos adotados foram a pesquisa documental e o estudo de campo, ocorrido no período de outubro de 2015 a janeiro de 2016, em nove feiras livres, valendo-se das técnicas de entrevista e observação in loco. A análise aponta entre os principais resultados: i) predomínio de feirantes oriundos de uma agricultura convencional, que conta com a força de trabalho familiar; ii) desinteresse do jovem pelo trabalho do campo; iii) feirantes que, na sua maioria, admitem o uso de insumos químicos no processo de cultivo de alimentos; iv) falta de assistência de técnica e de orientação por parte do poder público e de entidades ligada ao setor; v) infraestrutura carente e inadequada de trabalho dos feirantes, além de problemas no cumprimento das normas higiênicosanitárias. Conclui-se, a necessidade de melhor organização, formação e assistência técnica aos feirantes, pois requer melhorias no trabalho, na produção e no comércio, e consequentemente, uma ação mais efetiva para o fortalecimento da agricultura familiar e da atividade laboral do feirante; assim como, a necessidade de um programa de qualificação às feiras livres, para que possa assegurar sua continuidade e espaço mercadológico.
\end{abstract}

Palavras-chave: Feiras Livres. Sustentabilidade. Agricultura Familiar. Ciências Ambientais.

\section{THE STREET FAIR ENTERPRISES OF THE MUNICIPALITY OF SANTA MARIA/RS - CHARACTERIZATION AND SUSTAINABILITY}

\begin{abstract}
The street fairs are of great importance to the local community, rural man and family agriculture, for they present themselves as a way of developing and strengthening the productive chain. The present article seeks to characterize the enterprises of the street fairs of the municipality of Santa Maria/RS, and to ascertain their sustainability under the social, economic and environmental aspects. The methodological procedure adopted
\end{abstract}

1 Doutoranda em Ambiente e Desenvolvimento da Universidade do Vale do Taquari - Univates. Mestre em Engenharia de Produção pela Universidade Federal de Santa Maria, UFSM (2002).

2 Doutor em Matemática pela Universidade Federal do Rio Grande do Sul, UFRGS (2000). Professor Titular da universidade do Vale do Taquari - Univates. Atua no Programa de Pós-Graduação Ambiente e Desenvolvimento (Mestrado e Doutorado) e nos Cursos de Graduação da Univates. 
was the documentary research and field study, which took place in the period from October 2015 to January 2016, in nine street fairs, using the techniques of interview and observation in loco. The analysis points among the main results: i) predominance of farmers from a conventional agriculture, which counts on the family labor force; ii) disinterest of the youth for the work of the field; iii) farmers who, for the most part, admit the use of chemical inputs in the process of growing food; iv) lack of technical assistance and guidance from public authorities and entities related to the sector; $v$ ) needy and inadequate workplaces of the fairs, as well as problems in complying with hygiene and health standards. It is concluded that there is a need for better organization, training and technical assistance to farmers, because it requires improvements in work, production and trade, and consequently, a more effective action to strengthen family farming and the labor market of the marketer; as well as, the need for a program to qualify for free trade fairs so that it can ensure its continuity and market space.

Keywords: Street Fair. Sustainability. Family Farming. Environmental Sciences.

\section{INTRODUÇÃO}

As feiras livres são espaços revestidos de significados e de simbolismo, onde "as multiplicidades se manifestam e se complementam" (REIS; VIEIRA, 2011, p. 8). São ambientes configurados pelo forte aspecto social, onde as trocas, o ponto de encontro, as interaçóes e as proximidades acontecem, e pelo aspecto econômico, onde o comércio e a produçáo local aparecem (MINNAERT, 2008; REIS; VIEIRA, 2011).

As feiras livres são lugares de identidade própria, de tradiçóes e de culturas enraizadas. São atividades que resistem ao tempo, desde o surgimento no Brasil, no período da colonização até os dias atuais, mantém a sua finalidade que é de suprir a demanda de abastecimento alimentar (PIERRI; VALENTE, 2010; PINTO; MORAES, 2011; SOUZA, 2015).

Segundo o mapeamento do Ministério do Desenvolvimento Social e Combate à Fome há 6,4 mil feiras no Brasil, sendo que 5.119 são feiras livres e 1.331 são feiras agroecológicas ou com produção orgânica. Esse dado é resultante de uma pesquisa realizada, em agosto a novembro de 2014, junto a 1.628 municípios, além de 23 estados e do Distrito Federal (SNA, 2015).

Como pode-se observar, as feiras livres estão marcando presença e resistindo ao poderio das grandes redes supermercadistas, considerando que estas redes apresentam uma infraestrutura física e tecnológica muito superior às feiras livres, além da "logística, segurança, formas de pagamento e horário amplos de atendimento” (FEIRAS, 2008, p. 1, texto digital).

A importância e o papel que as feiras livres desempenham no cenário socioeconômico são predicados que motivaram a realização deste estudo. Além destes, mais duas razóes justificaram o desenvolvimento desta pesquisa, são elas:

- Primeiro, considerando que o perfil do consumidor está mudando, tornando-se cada vez mais criterioso na escolha de alimentos e, junto a isso, desenvolvendo hábitos mais saudáveis, começando pela alimentação (SOUZA, 2006). Em vista disso, a feira livre aparece como uma alternativa ao consumidor de encontrar alimentos que possam atender suas expectativas. De acordo com Kinjo e Ikeda (2005, p. 17), a "feira livre está posicionada como o local onde são vendidos produtos de qualidade, frescos e de preços atraentes". 
- Segundo, a produção de alimentos hortifrutigranjeiros de Santa Maria/RS não está dando conta da demanda consumidora. De acordo com a Secretaria Municipal de Desenvolvimento Rural (SMDR), a insuficiência produção primária local acarreta numa perda econômica significativa para município, um valor estimado de $\mathrm{R} \$ 310,5$ milhóes por ano, pois as redes supermercadistas devem comprar produtos de estabelecimentos situados fora do município, o que comprova a necessidade de investimento do setor primário, sobretudo, da agricultura familiar (SANTA MARIA, SMDR, 2015).

Vale destacar que, em Santa Maria, a agricultura familiar é desenvolvida nos distritos que, por sua vez, estão situados no meio rural e possuem uma área territorial de 1.510,60 $\mathrm{km} 2$, ocupando $85 \%$ da área do município, visto que o seu total é de $1.781,8 \mathrm{~km}^{2}$ (FEE, 2015). No entanto, o setor primário aparece na terceira posição de atividade econômica do município, conforme a Agência de Desenvolvimento de Santa Maria (ADESM, 2015). A sua estrutura fundiária apresenta 14.371 estabelecimentos rurais, sendo que 79,37\% destes estabelecimentos pertencem à agricultura familiar (IBGE, 2006).

$\mathrm{Na}$ visão de Nunes e Karnopp (2013), os produtos que vêm sendo comprados pelo município, não exigem alto investimento para o seu cultivo e nem escala de produção. A estrutura fundiária tem condiçóes de abarcar essa produção, se apresentando, portanto, como uma alternativa de desenvolvimento endógeno para Santa Maria.

Isto posto, todas essas premissas reforçam a necessidade de se adotar açóes que permitam a continuidade das feiras livres, bem como, de alavancar a produçâo desenvolvida pelos produtores feirantes, pois a feira depende do produtor. E, a recíproca não deixa de ser verdadeira, visto que muitos feirantes têm a feira como o seu único ponto de venda de seus produtos (FELIN; MIORIN, 2006).

Tendo em vista a importância da feira livre para a economia local, para o sustento das famílias produtoras feirantes, para o abastecimento alimentar e para o consumidor, que confia na procedência e na qualidade do produto, fazendo-o com que vá à feira ao invés de outro local, que esta investigação ganha relevância.

$\mathrm{O}$ presente artigo buscou caracterizar os empreendimentos de feiras livres do município de Santa Maria/RS, e averiguar sua sustentabilidade sob os aspectos - social, econômico e ambiental.

\section{SUSTENTABILIDADE - UM CONTEXTO GERAL}

Segundo Santos e Cândido (2010, p. 4), “o modelo de crescimento econômico norteado pela globalização e pelos avanços tecnológicos, promoveram, por um lado, a elevação dos índices econômicos e, por outro lado, a contribuição decisiva para a degradação ambiental".

Os principais impactos que esse modelo acarretou ao meio ambiente, de acordo com Cavalcanti (2003) apud Santos e Cândido (2010, p. 2) são:

a contaminação de rios, as restriçôes no abastecimento de água, a proliferação de doenças, as elevadas concentrações de $\mathrm{CO} 2$ na atmosfera, o efeito estufa, o aumento do "buraco" na 
camada de ozônio, o empobrecimento do solo, a extinção das espécies devido à degradação de hábitats, as mudanças no clima, dentre outros malefícios.

Vale ressaltar que os reflexos desse modelo não se restringem somente à faixa ambiental, mas também, ao campo social, econômico e cultural, provocando transformaçôes na organização das cidades e do campo. No meio rural houve o que denomina Brandemburg (2010) de rural moderno, uma produção não mais voltada para a subsistência familiar, mas, também para atender o mercado. Segundo o autor, "a agricultura modifica seus métodos e em certa medida se industrializa, e o rural gradativamente é dotado de uma infraestrutura urbana" (BRANDEMBURG, 2010, p, 423).

A Revolução Verde impulsionou a modernização e industrialização da agricultura. Foi um processo que se iniciou na década de 60 e se caracterizou fundamentalmente pela "combinação de insumos químicos (fertilizantes, agrotóxicos), mecânicos (tratores e implementos) e biológicos (sementes geneticamente melhoradas)" com a idealização de um upgrade no sistema agrícola (ALBERGONI; PELAEZ, 2007, p. 34).

Conforme aborda Pereira Filho (1991, p. 56), a revoluçâo verde conseguiu

elevar a produtividade e o rendimento econômico de algumas culturas, mas, ao mesmo tempo, aumentou a concentração das riquezas, agravou problemas sociais, elevou o consumo energético nos agroecossistemas, acelerou o processo de degradação ambiental e o aumento dos custos de produção.

Assim, nota-se que tal modelo de produção teve também desdobramentos positivos como o eficiente sistema de treinamento, a assistência técnica, a extensão rural e o crédito agrícola (FALEIRO, 2012). Dessa maneira, ao proporcionar uma maior produtividade na produção agrícola, o sistema elevou significativamente seus índices de desempenho, conforme apresenta Marouelli (2003, p. 07):

\footnotetext{
No que se refere ao aumento da produção total da agricultura, a Revolução Verde foi, na época, um sucesso. Entre 1950 e 1985, a produção mundial de cereais passou de 700 milhôes para 1,8 bilhão de toneladas, uma taxa de crescimento anual de $2,7 \%$. Neste período, a produçáo alimentar dobrou e a disponibilidade de alimentos por habitante aumentou $40 \%$, parecendo que o problema da fome no mundo seria superado pelas novas descobertas.
}

Portanto, a partir dessa modernizaçáo consegue-se uma maior produtividade por meio da "artificial conservação e fertilização do solo, da mecanização da lavoura, da seleção de sementes e de outros recursos" (TEIXEIRA, 2005, p. 23).

Gonçalves Neto (1997, p. 78) complementa que, para atingir o grau de produtividade, os agricultores tinham a seu favor uma "[...] política de créditos facilitados". Consequentemente, esta agricultura passou a ficar dependente do setor econômicofinanceiro e industrial, impactando as condiçôes ambientais e causando desequilíbrio social (BALSAN, 2006).

Neste aspecto socioeconômico, houve um aumento significativo do desemprego, do empobrecimento e do êxodo rural. A elevada concentraçáo de terra e a desigualdade na 
distribuição de renda nos países em desenvolvimento acarretaram uma imensa exclusão social (MOREIRA, 2000).

Dentro desse contexto, um grande número de agricultores foi à decadência. Assim, grande parte da população rural veio a se favelizar nas periferias urbanas, fato que trouxe o aumento da pobreza rural, a elevação da violência para níveis altíssimos, o aumento da criminalidade e da destruição ambiental (VEIGA, 2000).

Todo esse cenário negativo, gerado pelo modelo desenvolvimentista, passou a ser ponto de pauta em diversos eventos, resultando ao final dessas conferências, diretrizes e normas que expressavam intençóes de açóes que promovesse o desenvolvimento econômico aliado à proteçấo e a preservaçáo do meio ambiente.

A partir de entáo, um novo modelo de desenvolvimento passou a ser desejado, expresso no Relatório de Brundtland, em 1987, um modelo que traz o conceito de Desenvolvimento Sustentável que, na sua essência, traduz como "um processo de mudança no qual a exploração dos recursos, do direcionamento dos investimentos, a orientação do desenvolvimento tecnológico e a mudança institucional estâo em harmonia e reforçam o atual e futuro potencial para satisfazer as aspiraçôes e necessidades humanas" (PORTAL ONUBR, 2014, p. 1, texto digital).

Outro importante documento que merece destaque é a Agenda 21, definida como "instrumento de planejamento para a construção de sociedades sustentáveis, em diferentes bases geográficas, que concilia métodos de proteção ambiental, justiça social e eficiência econômica" (BRASIL, MMA, 1992, texto digital). A Agenda 21 é um documento que foi acordado e assinado por 179 países participantes da Rio 92 (BRASIL, MMA, 1992). Este documento é constituído de 40 capítulos, dentre eles, vale destacar o Capítulo 14 Promoção do Desenvolvimento Rural e Agrícola Sustentável que, no bojo de seu conteúdo, no item 14.2, apresenta:

\footnotetext{
O principal objetivo do desenvolvimento rural e agrícola sustentável é aumentar a produção de alimentos de forma sustentável e incrementar a segurança alimentar. Isso envolverá iniciativas na área da educação, o uso de incentivos econômicos e o desenvolvimento de tecnologias novas e apropriadas, dessa forma assegurando uma oferta estável de alimentos nutricionalmente adequados, o acesso a essas ofertas por parte dos grupos vulneráveis, paralelamente à produção para os mercados; emprego e geração de renda para reduzir a pobreza; e o manejo dos recursos naturais juntamente com a proteçấo do meio ambiente (BRASIL, MMA, 1992, texto digital).
}

Em síntese, as diretrizes básicas do desenvolvimento rural sustentável são de promover a segurança alimentar, gerar emprego e renda, conservar os recursos naturais e proteger o meio ambiente (SANTOS; PIASENTIN, 2010).

A agricultura, como qualquer outra atividade humana, para se manter sustentável deverá levar em consideração, simultaneamente, as dimensōes "econômica", "ambiental" e "social", ou seja, impóe-se a combinação da eficácia econômica e da gestão racional do meio ambiente e do tecido social (ANGLADE, 1999).

Mas o que é uma agricultura sustentável? Para responder essa pergunta, é importante, primeiramente, trazer o conceito de sustentabilidade. Para Sartori, Latronico e Campos 
(2014, p. 11), o conceito de sustentabilidade é complexo e contínuo, se apresenta em "uma grande variedade de assuntos, de diversas áreas e com diferentes enquadramentos”.

Nesse sentido torna-se difícil de precisar o conceito de sustentabilidade, mas Barbosa (2008, p. 10), contribui expondo que sustentabilidade consiste em "encontrar meios de produção, distribuição e consumo dos recursos existentes de forma mais coesiva, economicamente eficaz e ecologicamente viável”.

Já os autores Melo e Cândido (2013, p. 5) afirmam que a sustentabilidade deve

[...] voltar a atençâo para uma das áreas mais críticas do desenvolvimento, a agricultura, por se tratar de um setor essencial à sobrevivência humana, e cujas atividades, desde os primórdios da civilização, vêm causando alteraçôes profundas nos ambientes naturais, gerando os mais diversos impactos ambientais, sociais e econômicos (MELO; CÂNDIDO 2013, p. 5).

Neste contexto, muitos estudiosos estão voltando seus estudos para encontrar melhores métodos de produção agrícola e utilização de recursos que não agrida o meio ambiente, buscando empreender uma agricultura com status de sustentável. A agricultura sustentável, no entendimento de Gliessman (2001), é um processo que reconhece a natureza sistêmica da produção de alimentos, forragens e fibras, equilibrando com equidade, preocupaçóes relacionadas à saúde ambiental, justiça social e viabilidade econômica entre os diferentes setores da populaçáo, incluindo distintos povos e diferentes geraçóes.

Ao encontro disso, Peche Filho (2015, p.1) discorre sobre código de conduta de boas práticas ambientais na agricultura, que "são atitudes e formas de gestão que compõem um código para orientação e redução dos efeitos negativos das atividades humanas sobre o ambiente".

Para obtenção de uma agricultura sustentável há autores que consideram que a agricultura familiar seja o caminho. Prova disso, a própria Organização das Naçôes Unidas para a Alimentação e a Agricultura (FAO) faz essa reverência, tanto que, em 2014, celebrou o "Ano Internacional da Agricultura Familiar", devido por

preservar os alimentos tradicionais, contribuir para uma alimentação balanceada, proteger agrobiodiversidade e pelo uso sustentável dos recursos naturais. A agricultura familiar representa uma oportunidade para impulsionar as economias locais, especialmente quando combinada com políticas específicas destinadas a promover a proteção social e o bem-estar das comunidades (FAO, 2014, p.1).

Para Olalde (2004) a agricultura familiar favorece o emprego de práticas produtivas ecologicamente mais equilibradas, como a diversificação de cultivos, o menor uso de insumos industriais e a preservação do patrimônio genético.

De acordo com Carneiro e Maluf (2003) a agricultura familiar tem como função a conservação dos recursos naturais e manutenção da paisagem rural, em adição a este, também tem como funções: reprodução socioeconômica das famílias rurais; características técnico-produtivas, promoção da segurança alimentar das próprias famílias rurais e da 
sociedade e sustentabilidade da atividade agrícola; e manutenção do tecido social e cultural associado a determinado território.

Pode-se inferir, em linhas gerais, que a sustentabilidade está relacionada ao bem-estar social, a qualidade de vida, sobretudo, ao bom senso na utilização dos recursos naturais, sem que comprometa o ecossistema. E, diante do desafio de alcançar a sustentabilidade ambiental, principalmente, no que se refere ao setor da agricultura, em que a produçáo de larga escala permanece se sobrepondo ao cuidado com a natureza, eis que a agricultura familiar volta a ser reconhecida pela sua prática e função socioeconômica.

\section{FEIRAS LIVRES - SURGIMENTO E CARACTERÍSTICAS}

No Brasil, as feiras livres são decorrentes da colonização portuguesa e surgem por volta do século XVII com a finalidade de suprir a "necessidade de abastecimento alimentar e da comercialização do excedente produzido no campo" (PINTO; MORAES, 2011, p. 2).

As primeiras evidências de feiras livres no Brasil "remontam ao ano de 1548, quando o rei de Portugal, D. João III, preocupado em evitar o êxodo rural na colônia, instituiu um dia de feira nas cidades" (MENEZES, 2005, p. 9).

Segundo Mott (1975) (apud Azevedo; Queiroz, 2013), o primeiro registro oficial de feira livre no Brasil foi em 1732, a feira de Capoame, localizada no Recôncavo Baiano. A partir de então, as feiras se estenderam não só por todo o nordeste brasileiro, como também, em outras regiōes do país.

Quanto à conceituação de feira livre, pode ser configurada conforme sua conotação, uma delas pode ser voltada pelo aspecto social, como colocam os autores Mota et al. (2012, p.4) que, a "feira é um espaço polissêmico, em que vidas se cruzam, convivem e experimentam um cotidiano de diversidades". De outro ângulo, as feiras livres podem ser compreendidas sob ponto vista cultural, pois são ambientes que proporcionam um elo entre meio rural e urbano e funcionam como ponto de encontro e de movimentação de pessoas, de valorização e de expressão da cultura local (SILVA et al., 2014). A considerar que, as feiras livres além de proporcionar aproximação e interação entre clientes e feirantes, também podem promover uma "troca de saberes entre a cidade e o meio rural" (NORA; DUTRA, 2015, p. 52). Vale destacar que, as feiras livres são espaços de muitos contrastes, como evidencia Menezes (2005, p. 41) colocando que a feira é

um lugar onde trafegam lado a lado pobres e ricos, velhos e jovens, mendigos e vendedores de santinhos. Ela é composta de uma caoticidade de traços, cores, sons, sotaques, roupas, cheiros, volumes, movimentos, enfim uma representaçáo fiel dos signos da cidade antiga e moderna, todos dispostos em seu território articulado.

Essa mescla de diferenças e de simbologias fazem com que as feiras livres sejam eventos diferenciados aos demais canais de comercialização, por possuir características muito peculiares no âmbito sociocultural. Por conta dessas peculiaridades, que as feiras livres vêm se perpetuando, na concepção de Lima e Sampaio (2009, p. 6) as feiras "atravessaram os tempos" devido a sua capacidade de "adaptar-se a cada sociedade e aos tipos de economias". 
$\mathrm{Na}$ compreensão de Morel, Rezende e Sette (2015, p. 48) as feiras livres devem ser entendidas como uma "ação social, que proporciona benefícios econômicos e sociais aos pequenos proprietários rurais"; já para os municípios, podem ser concebidas como um "negócio, gerador de emprego e renda". Carvalho (2016, p. 1) corrobora que as feiras podem trazer ganhos ao município, devido:

\begin{abstract}
a) a valorização da identidade regional, da tradição e da cultura; b) a geração de trabalho, de ocupação e de renda; c) a dinamização da economia dos pequenos municípios; d) a promoção da segurança alimentar e nutricional sustentável; e) o abastecimento regular de alimentos de qualidade, adaptado aos hábitos culturais da população local; f) o fortalecimento do associativismo e promoção da gestão coletiva.
\end{abstract}

Tendo em vista, o quanto as feiras livres representam, que se faz necessário o poder público se articular com produtores e entidades ligadas ao setor e promover açóes que visem o fortalecimento desses espaços, o aprimoramento do lado empreendedor do feirante, assim como, o melhoramento de sua condição estrutural, gestão e atendimento ao público.

\title{
4 PERCURSO METODOLÓGICO
}

A pesquisa se caracteriza, quanto a sua natureza, como aplicada, de abordagem do problema qualitativa. Em relação aos seus objetivos, a pesquisa se enquadra como exploratória e descritiva. Quanto ao método, a pesquisa se identifica como indutiva. A respeito da coleta de dados, esta etapa está subdividida em duas fases: pesquisa documental e pesquisa de campo.

Para o desenvolvimento da pesquisa de campo, foram selecionadas, como técnicas de coleta de dados: entrevistas e observação in loco. As entrevistas transcorreram de outubro de 2015 a janeiro de 2016, foram gravadas e transcritas para a sua análise. As entrevistas foram guiadas por um roteiro, composto por questôes abertas e fechadas, e específico, para cada tipo de sujeito entrevistado. A pesquisa contou com a participação de 32 feirantes, 25 consumidores, um representante da Secretaria Municipal de Desenvolvimento Rural e dois representantes da Emater Municipal, totalizando, portanto, 60 sujeitos entrevistados.

A observação foi outra técnica de coleta de dados, que foi realizada na oportunidade das visitas às feiras, possibilitando a pesquisadora analisar as condiçóes de trabalho dos feirantes e os aspectos higiênico-sanitários. A observação ocorreu em nove feiras livres e, para tal, utilizou-se um diário de campo que serviu como um instrumento que auxiliou a pesquisadora a fazer registros do cotidiano dos feirantes e do que acontece nas feiras.

A outra fase de estudo foi a pesquisa documental, pelo qual foram obtidos os dados secundários, conseguidos por meio de uma análise de documentos, relatórios, legislaçóes, folders, folhetos, notícias de jornais, site na internet, revistas, documentários e publicaçóes acadêmicas. Esses dados complementaram os dados primários e ajudaram a pesquisadora a ter uma visáo global do objeto de estudo.

A análise de dados qualitativos se realiza sob o método de Moraes e Galiazzi (2007) que consiste na análise textual discursiva. Na citação de Andrade (2011, p. 56), "essa análise pode ser realizada com textos já existentes ou com textos que serão produzidos por meio de 
entrevistas e observações - documentos produzidos, especificamente, para a pesquisa”. E, os dados quantitativos resultantes da pesquisa de campo foram tabulados e organizados com auxílio do Software Office Excel ${ }^{\oplus}$ versão $2013^{3}$ da Microsoft ${ }^{\bullet}$.

\section{AS FEIRAS LIVRES DE SANTA MARIA/RS}

Primeiramente, foi realizada a entrevista com o representante da Secretaria Municipal de Desenvolvimento Rural (SMDR) e, posteriormente, com os técnicos da Emater, a fim de identificar a atuação desses órgáos, como também às políticas públicas direcionadas para agricultura familiar e para as feiras livres do município.

$\mathrm{Na}$ intenção de fortalecer a agricultura familiar do município, a SMDR em parceria com a Emater implementaram, em 2012, 14 programas (Pró-Agroindústria, Pró-Calcário, Pró-Cria, Pró-Flores, Pró-Floresta, Pró-Frango, Pró-Frutas, Pró-Horta, Pró-Leite, Pró-Mel, Pró-Oliveira, Pró-Ovino, Pró-Peixe e Redes), que concede aos agricultores familiares um aporte financeiro, no intuito de alavancar a sua produção, aumentar a sua renda, melhorar a sua qualidade de vida e atender à demanda de consumo do município. Para conseguir o ingresso de um desses programas, o produtor deverá pertencer algum tipo de organizaçấo coletiva, preferencialmente, cooperativa ou associação. Somado a esses programas, a Prefeitura desenvolveu dois projetos: i) a construção de poços artesianos, de redes de distribuição e de cisternas e ii) a construção de micro açudes e tanques para piscicultura.

Também, instituiu o Fundo Rotativo ${ }^{4}$, que se trata de um contrato de financiamento destinado, prioritariamente, aos empreendimentos realizados por meio de associaçóes, cooperativas e condomínios rurais de produtores rurais. Para contratos de financiamentos individuais serão disponibilizados aos que possuem propriedades iguais ou menores de quatro módulos rurais.

Outra ação da Prefeitura foi o lançamento do selo de certificação "sabor do coração", no ano de 2010. Agregar essa marca ao produto significa que a produçáo e o beneficiamento teve acompanhamento técnico, observando as boas práticas de produção e a legislação sanitária e ambiental, como também o identificando como um produto de Santa Maria/ RS. Os produtores que desejarem utilizar este selo, deverão se cadastrar em um dos catorze programas municipais de desenvolvimento rural.

Em adiçáo, a prefeitura promove dois eventos de grande porte, sendo um anual, e o outro, de periodicidade não definida, pois apresenta várias ediçóes durante o ano, respectivamente, trata-se da Feira dos Distritos e do Pátio Rural. Esses eventos objetivam evidenciar a riqueza e a qualidade dos produtos coloniais e, mostrar a diversidade artística, cultural e culinária dos nove distritos de Santa Maria.

Para as feiras livres, especificamente, o poder público possui um projeto futuro, que é de construir um terminal de comercialização, para que os feirantes possam ter melhores

3 C 2016 Microsoft. Disponível em: <http://office.microsoft.com/pt-br/default.aspx>. Acesso em: jul. 2016.

4 O Fundo Rotativo foi criado pela Lei Municipal no 3.962, de 27 de março de 1996. Disponível em: <https://camara-municipal-da-santa-maria.jusbrasil.com.br/legislacao/540683/lei-3962-96>. 
condições de trabalho e uma infraestrutura mais equipada e qualificada para melhor atender seus clientes.

De acordo com o representante da SMDR, o município de Santa Maria/RS tem 14 feiras livres. Ao realizar a pesquisa de campo, observou-se que três feiras se realizam esporadicamente e duas feiras não ocorrem mais. No entanto, nove feiras livres são realizadas com periodicidade semanal, sendo este o critério determinante pela escolha destas para desenvolver a presente pesquisa.

As feiras livres de Santa Maria ocorrem em cinco bairros e juntas totalizam 67 bancas. Importante registrar que há uma rotatividade de feirantes nas feiras, ou seja, a maioria deles participam de mais de uma feira, pois cada feira tem dias predefinidos, diferenciados, escalonados em seis dias da semana (segunda-feira a sábado). Isso é regulamentado pelo órgão público municipal, o que possibilita ao feirante comercializar seus produtos em mais de uma feira livre. A partir disso, tem-se um universo de 51 feirantes.

\subsection{Caracterizaçáo dos feirantes}

O estudo revelou que 22 dos 32 feirantes entrevistados são do sexo masculino, enquanto que 10 feirantes são do sexo feminino. Em relação à idade, 16 feirantes se enquadram na faixa etária de 31 a 50 anos, 14 feirantes estão entre 51 a 70 anos e 02 feirantes possuem mais de 71 anos de idade.

No que se refere à escolaridade, 22 feirantes não terminaram o Ensino Fundamental, 05 feirantes não completaram o Ensino Médio, 02 feirantes possuem o Ensino Médio completo e 03 feirantes têm um Curso Superior.

A respeito da procedência, verificou-se que 21 feirantes residem em algum distrito do município de Santa Maria, 10 feirantes moram em um bairro da cidade e 01 feirante reside em uma cidade circunvizinha.

A profissão feirante, para 25 entrevistados, é uma ocupação profissional herdada de seus pais, uma vez que desde muito jovens os acompanhavam nas atividades da feira e os auxiliavam na produção. Já para 07 entrevistados, ser feirante foi uma escolha atrelada a outro motivo; seja para complementar a renda familiar ou por falta de emprego.

Quanto ao tempo de trabalho, 18 feirantes atuam há mais de 20 anos, dentro deste grupo, encontram-se 05 feirantes que estão há mais de 40 anos nas feiras. Os que estão na atividade de 10 a 20 anos correspondem a 08 feirantes, e os que atuam há menos de 10 anos são 06 feirantes.

Como se pode perceber, o perfil dos feirantes pode ser configurado como um grupo de trabalhadores, predominantemente do sexo masculino, com ensino fundamental incompleto, de faixa etária heterogênea, com mais de 20 anos de atuação, oriundos de um dos nove distritos de Santa Maria. E, para a maioria deles, ser feirante foi uma atividade herdada naturalmente de seus pais. 


\subsection{Os empreendimentos de feiras livres sob os aspectos sociais, econômicos e ambientais}

As informações obtidas da pesquisa estão compiladas no quadro 1, que apresenta os resultados sob as dimensōes: social, econômica e ambiental.

Quadro 1 - Resultados encontrados dos empreendimentos de feiras livres, sob os aspectos socioeconômicos e ambientais

\begin{tabular}{|c|c|c|c|}
\hline Dimensão & Indicadores & Variáveis & Resultados \\
\hline \multirow{13}{*}{ Social } & \multirow[t]{2}{*}{ Assistência técnica } & Possui & 06 \\
\hline & & Não possui & 26 \\
\hline & \multirow[t]{2}{*}{ Capacitação } & Participam & 08 \\
\hline & & Não participam & 24 \\
\hline & \multirow[t]{3}{*}{ Organização produtiva } & Cooperados & 07 \\
\hline & & Sindicalizado & 05 \\
\hline & & Não pertencem O.P. & 20 \\
\hline & \multirow[t]{3}{*}{ Programas de governo } & PRONAF & 03 \\
\hline & & Programa da SMDR & 01 \\
\hline & & Náo tem acesso & 28 \\
\hline & \multirow[t]{3}{*}{ Sucessão familiar } & Não tem & 23 \\
\hline & & Possui & 06 \\
\hline & & Não tem filhos & 03 \\
\hline \multirow{18}{*}{ Econômica } & \multirow[t]{2}{*}{ Controle financeiro } & Manual & 30 \\
\hline & & Planilha eletrônica & 02 \\
\hline & \multirow[t]{2}{*}{ Custeio de produção } & Recursos próprios & 28 \\
\hline & & Programas governamentais & 04 \\
\hline & \multirow[t]{2}{*}{ Destino dos produtos } & Exclusivo p/ feiras & 24 \\
\hline & & Feiras e outros locais & 08 \\
\hline & \multirow[t]{2}{*}{ Diversificação de produtos } & Realiza & 30 \\
\hline & & Não realiza & 02 \\
\hline & \multirow[t]{2}{*}{ Fonte de renda } & Feira livre principal & 26 \\
\hline & & Feira livre complementar & 06 \\
\hline & \multirow[t]{2}{*}{ Máo de obra } & Familiar & 28 \\
\hline & & Terceirizada & 04 \\
\hline & \multirow[t]{3}{*}{ Procedência dos produtos } & Própria & 26 \\
\hline & & Mista & 04 \\
\hline & & Terceiros & 02 \\
\hline & \multirow[t]{3}{*}{ Posse da Terra } & Própria & 29 \\
\hline & & Arrendada & 01 \\
\hline & & Não tem & 02 \\
\hline
\end{tabular}




\begin{tabular}{|c|c|c|c|}
\hline Dimensão & Indicadores & Variáveis & Resultados \\
\hline \multirow{16}{*}{ Ambiental } & \multirow[t]{2}{*}{ Coleta seletiva } & Realiza & 04 \\
\hline & & Não realiza & 28 \\
\hline & Condiçóes higiênico-sanitárias & $\begin{array}{l}\text { 1.Instalaçóes, equipamentos, } \\
\text { móveis, utensílios; } \\
\text { 2. Higiene pessoal; } \\
\text { 3. Embalagens; } \\
\text { 4. Ventilação e refrigeração }\end{array}$ & 32 \\
\hline & \multirow[t]{4}{*}{ Gestão de resíduos da feira } & Adubo & 23 \\
\hline & & Doação & 04 \\
\hline & & Lixo & 04 \\
\hline & & Outro & 01 \\
\hline & \multirow[t]{4}{*}{ Gestão de resíduos de produção } & Adubo & 19 \\
\hline & & Alimentação de animais & 08 \\
\hline & & Lixo & 04 \\
\hline & & Outro & 01 \\
\hline & \multirow[t]{4}{*}{ Sistema de cultivo } & Insumos químicos (somente) & 25 \\
\hline & & Insumos químicos + orgânico & 04 \\
\hline & & Orgânico (somente) & 02 \\
\hline & & $\begin{array}{l}\text { Não se aplica (feirante trabalha } \\
\text { exclusivamente com artesanato) }\end{array}$ & 01 \\
\hline & Supervisão dos órgãos públicos & Não possui & 32 \\
\hline
\end{tabular}

Fonte: Pesquisa de campo (2016).

Dos resultados apontados no quadro 1, pode-se constatar que os feirantes apresentam algumas dificuldades e carências, entre elas está a falta de articulação entre os feirantes. Os dados revelam que, a maioria não possui assistência técnica, não se capacitam e não estão organizacionalmente estruturados, ou seja, não pertencem a uma associaçáo/cooperativa ou outro tipo de ação coletiva. A importância de uma organização está, seja ela qual for o tipo, quando, "bem estruturada, pode viabilizar técnica e economicamente os pequenos produtores rurais" (NANTES; SCARPELLI, 2012, p. 647).

Isso pode ser comprovado, ao conferir o relato de um dos feirantes cooperados, que cita algumas vantagens que passou a obter, quando ingressou em uma cooperativa:

(F. 4) mais respaldo para se inserir no mercado, cria canais, respaldo técnico, vantagem maior ao produtor do que não é cooperado, gama de informaçóes, troca de ideias, experiências e soluçóes.

A falta de assistência técnica e de capacitação dos feirantes pode estar associada a essa falta de articulação. A decisão por qualquer um dos tipos de organizaçóes de ação coletiva deve partir dos próprios feirantes, com estudo mais aprofundado sobre cada uma delas, vislumbrando o que seria mais interessante para o momento, e qual delas possibilitaria maior retorno às suas necessidades. Vale registrar que, por meio de uma ação coletiva, os feirantes poderão obter maiores facilidades na obtenção de assistência técnica, capacitações, inclusive no ingresso de um dos catorze programas de desenvolvimento rural do município. Lembrando que, esses programas não são financiamentos, e sim, investimentos 
aos agricultores familiares que, de contrapartida, o produtor deve-se comprometer no cumprimento das diretrizes estabelecidas do programa escolhido.

Outro dado preocupante é a falta de sucessão familiar. O desinteresse do jovem pelas atividades do campo é alarmante, é uma situação que poderá comprometer a continuidade da produção agrícola. Muitas podem ser as razóes que levam o jovem a buscar por outro caminho profissional, uma delas pode ser por "incentivo feito pelos próprios pais, por pensarem que os filhos terão melhor qualidade de vida na zona urbana, sendo profissionais assalariados ou por causa do próprio sistema patriarcal, que não dá oportunidade ao jovem no meio rural" (DORNELES; HILLESHEIM, 2014, p. 138). Ou, pela falta de uma educação contextualizada com as necessidades do campo (SUCESSÃO, 2012). Sem dúvida, as escolas rurais carecem de investimento, isso permeia desde melhorias nas instalaçóes físicas das instituiçóes, como na capacitação de professores e de um currículo em sintonia com as questóes rurais.

Quanto ao aspecto ambiental, predomina feirantes que fazem uso do sistema de cultivo convencional. Segundo relato dos mesmos e dos técnicos da Emater, não há um programa de transição para agricultura orgânica, e o que há são pequenas açóes, que, gradativamente, estão trabalhando com uma agricultura de perspectiva agroecológica. Muitas são as dificuldades e empecilhos para que os produtores feirantes atuem numa produção orgânica, o que pode ser conferido em alguns relatos:

(F. 6) a produçâo de alimento orgânico requer mais custo, técnica e mão de obra; quem te disse que vende orgânico é mentira.

(F. 18) os produzir orgânicos é muito trabalhoso, então se faz uma produção pequena; para complementar a renda, necessitamos fazer páes, rapaduras, doces caramelizados, para conseguir ter um ganho.

(E. 1) há muitas barreiras para produção orgânica, produzir para comercializar, ai a questão muda. Para sobrevivência do produtor, ele precisa produzir em quantidade, para poder fazer uma renda. A produção orgânica exige mais trabalho por parte do produtor e mão de obra, aí o preço do produto fica bem mais caro; então, a produção existente é bem reduzida, ficando só para o autoconsumo.

A SMDR reconhece os desafios que os produtores possuem para passar da agricultura convencional para a agricultura orgânica. Portanto, faz-se necessário um programa específico que oriente e incentive o produtor a fazer, paulatinamente, essa transição. Sugere-se uma união de forças entre poder público, entidades, instituições de ensino superior, para a implementação de um programa/projeto que objetive a produção orgânica, e, chegue ao final desse processo, à certificação de produtos orgânicos.

Outro ponto a assinalar, é que em todas as feiras apresentam problemas em atender as normas higiênico-sanitárias. Tal constatação foi averiguada, a partir de uma análise in loco que se subsidiou da resolução da Anvisa, a RDC no 216/2004, observando as condiçóes de: 
a) Instalações, equipamentos, móveis e utensílios; b) Higiene pessoal; c) Embalagens; e d) Ventilação e refrigeração de produtos.

Ao analisar as instalaçóes, equipamentos, móveis e utensílios verificaram-se que, nas feiras, as bancas estão alocadas à beira das calçadas, avenidas ou na parte central de praças. Desse modo, não há padronização no tamanho e nem há estética, uma vez que cada feirante se responsabiliza pela montagem e desmontagem, como também pela limpeza do local. As bancas são cobertas por lonas, e os produtos ficam armazenados em caixotes de plástico ou de madeira, dependendo do tipo de produto. Muitas caixas ficam diretamente no chão, outras sobre uma mesa improvisada de madeira, ou na caçamba de caminhão/caminhonete ou Kombi.

Em relação ao abastecimento de água, não há torneiras disponíveis, o feirante deve levar suas próprias garrafas/galóes de água. Essa carência se revela prejudicial não só para seu consumo, como também, para a higiene de suas mãos e limpeza do local. Somado a isso, não há banheiros públicos disponíveis no espaço das feiras livres. Caso haver necessidade de uso, os feirantes e os clientes deverão se dirigir ao estabelecimento comercial mais próximo da feira.

Quanto às embalagens, observou-se que boa parte dos produtos é embalada, exceto frutas, legumes e verduras. Já as carnes, encontradas em uma única banca, parte do produto estavam em bandejas, expostas em cima da mesa, sem cobertura e sem uma refrigeração adequada, e o restante, estavam em uma caixa térmica. Para embalar os produtos a serem entregues ao cliente, as sacolas plásticas são usadas e custeadas pelos próprios feirantes.

Em complemento, a pesquisa revela que os feirantes apresentam boas iniciativas com relação à gestão de resíduos, destinando as sobras de produtos alimentares para adubo orgânico e para doação. Por outro lado, deve haver efetivo engajamento para a coleta seletiva, ou seja, um programa que ensine as pessoas a fazer a separação e destinação correta de todos os tipos de resíduos, e para isso, é fundamental a parceria entre o órgão público municipal, universidades e entidades da área ambiental para que se consolide uma prática adequada e sustentável.

No que tange à refrigeração de produtos, a caixa térmica é o dispositivo mais utilizado para transportar e refrigerar alimentos, sejam carnes ou massas. A ventilação dos alimentos também parece ser inadequada, pois, em dias quentes, o estado aparente dos produtos estava comprometido. Além disso, muitas bancas, embora cobertas por lonas, ficam posicionadas sob uma forte exposição solar, tornando-se ambientes desfavoráveis aos alimentos e desconfortáveis para os feirantes e clientes.

Quanto às condições higiênico-sanitárias das feiras, foi possível constatar inconformidades ligadas a todas as categorias analisadas, comprovando a falta de supervisão e de acompanhamento por parte dos órgáos públicos. Segundo os feirantes, "a vigilância sanitária aparece na feira somente quando há alguma denúncia; e a Prefeitura vem à feira, no final do ano, para solicitar aos feirantes a renovaçâo do alvará". Fica, portanto, evidente a necessidade de açóes corretivas e educativas.

Por fim, do aspecto econômico, prepondera feirantes que tem a feira livre como principal fonte de renda, que contam, restritamente, com a mão de obra familiar e com 
recursos próprios para empreender sua produção. Muitos feirantes, dos 32 entrevistados, 26 dizem comercializar produtos de sua própria produção e buscam diversificá-los, visto a quantia de produtos agroindustriais e de artesanato expostos nas bancas, tornando-se mais uma opção de compra para os consumidores, e para os feirantes produtores, a garantia de renda e fortalecimento de seu espaço. A iniciativa de diversificação de produtos se apresenta como uma boa estratégia para o feirante, como forma de atrair mais clientes e de aumentar seus lucros.

\subsection{Dos consumidores - percepçóes sobre a feira livre}

$\mathrm{O}$ estudo verificou que uma parte dos consumidores frequentam as feiras livres por muito tempo: dos 25 entrevistados, 16 dizem ir à feira há mais de 10 anos. A frequência dos consumidores também é expressiva, já que 17 dos 25 entrevistados dizem ir às feiras todas as semanas; os demais vão esporadicamente, ao menos duas vezes ao mês. As razóes que os levam a comprar os produtos na feira, e não em outro local, são os seguintes:

produto fresco; produto saudável; produto sem agrotóxico; produto colonial; produto com mais sabor e mais cheiro; produto caseiro, com procedência segura e, principalmente, sem agrotóxico (tornando-se, assim, um investimento em longo prazo, pois acaba sendo um beneficio para a própria saúde).

Os motivos elencados ratificam as afirmaçóes de vários autores, que postulam ser as feiras livres lugares onde se encontram produtos especiais e com identidade territorial, além de ser alimentos ligados à natureza, frescos e saudáveis. (MENASCHE, 2004; KINJO; IKEDA, 2005; PIERRI; VALENTE, 2010).

Quanto à preferência de banca, 13 consumidores responderam que têm preferência por determinadas bancas. Os principais motivos de preferência citados são: a qualidade dos produtos, o bom atendimento dos feirantes, a confiança, a boa relação e a amizade para com o feirante. Todas estas consideraçóes vão ao encontro do que diz Silva (2011, p. 43), pois nas feiras,

[...] perpassam as trocas de bens materiais e penetram em esferas permeadas de solidariedade e reciprocidade, que envolve amizade, confiança, camaradagem, jocosidade etc., configurando-o num mercado de bens simbólicos.

Em relação aos preços dos produtos, 14 consumidores disseram não se importar com o valor, pois vale pagar mais por um produto saudável e de boa procedência; 02 consumidores acreditam que os produtos da feira têm valor menor do que os dos supermercados; os demais consumidores compram somente os produtos que consideram ser de preço mais baixo.

Como se pode observar, a maioria dos consumidores se dispóe a pagar um valor a mais, por estarem certos de que os produtos que estão adquirindo são saudáveis, conforme se constata em algumas falas:

(C. 2) não me importo, devido à qualidade dos produtos, que são novos e frescos. 
(C. 21) são fresquinhos, de qualidade, é bom ver novidades, e outra, as pessoas precisam trabalhar e vivem disso, entäo quer ajudar.

Por último, foram solicitadas, aos consumidores, sugestôes que poderiam vir a melhorar a feira livre. Majoritariamente, requerem melhorias na organizaçáo e infraestrutura. Além disso, teve consumidores que fez outros apontamentos, como: preocupação com relação ao descarte de produtos não vendidos, à limpeza do ambiente, à ausência de lixeiras, à falta de banheiros químicos, à falta de acesso à água, à poluição do ar e sonora, à falta de cuidado no manuseio dos alimentos e inadequada refrigeraçáo e temperatura dos alimentos.

\section{CONSIDERAÇÓES FINAIS}

A caracterização dos empreendimentos de feiras livres de Santa Maria/RS é constituída de feirantes produtores, que são agricultores familiares, majoritariamente, sem ligação com qualquer um do tipo de ação coletiva, seja cooperativa ou associaçáo, o que ocasionou, por sua vez, o impedimento de acesso a programas e políticas de incentivo da Secretaria de Desenvolvimento Rural do município. A somar, têm-se outras consequências que se apresentam, principalmente:

- No que tange aos aspectos sociais, verificou-se a falta de capacitação dos feirantes, a falta de assistência técnica, a falta de interesse do jovem pelas atividades do campo e a falta de articulação entre os feirantes.

- Quanto aos aspectos ambientais, a pesquisa aponta que os feirantes produtores mantêm o sistema de cultivo convencional, pois não há um programa de transição para agricultura orgânica. Também, observou-se a falta de atendimento às normas de higienesanitárias, além do uso de sacolas plásticas e a necessidade de aprimorar a coleta seletiva.

- Dos aspectos econômicos, destaca-se que, majoritariamente, para os feirantes, a feira livre é a principal atividade econômica. Eles comercializam seus produtos exclusivamente para a feira, realizam sua própria produção, possuem propriedade rural e buscam diversificar seus produtos como método de agregar valor e gerar renda. Além disso, verificou-se que eles não fazem um efetivo controle financeiro, uma vez não possuem conhecimento mais aprofundado do que envolve a gestão financeira de um empreendimento.

A problemática descrita é preocupante e pode comprometer a sustentabilidade dos negócios e da feira livre propriamente dita. Essa premissa foi constatada pelos próprios feirantes ao relatarem que muitos colegas de profissão saíram da feira para migrar para outro espaço de mercado, justamente para garantir seu espaço e renda.

Tendo em vista o valor das feiras livres para os feirantes e para os consumidores, entende-se que esses espaços, assim como a produção desenvolvida pelos feirantes produtores, necessitam de incentivos que promovam os seus fortalecimentos e apoio que possibilitem as suas continuidades. Em síntese, aponta-se algumas açóes que poderiam ser implementadas, com vistas a sustentabilidade dos empreendimentos de feiras livres, são elas: 
- Acesso aos programas da SMDR e readequação dos mesmos, sugere-se, então, uma revisão da(s) cláusula(s) desses programas que limita o acesso dos feirantes, visto que $62 \%$ destes náo atendem ao critério de acesso por não pertencerem a nenhum tipo de organizaçáo coletiva (associação ou cooperativa).

- Articulação entre os feirantes, no sentido de não somente constituir uma associação ou cooperativa, uma decisão que cabe unicamente a eles, mas também no sentido de reconhecer a importância dessa articulação, que pode transcender a questão econômica, sobretudo, social. Dessa forma, estes trabalhadores (feirantes) serão vistos como grupo e terão a noção do valor do seu trabalho e do que representam para a sociedade e desenvolvimento local.

- Profissionalizaçáo dos feirantes por meio de uma parceria entre Prefeitura, Universidades e Emater que possibilitaria uma estruturação de um programa que prestasse consultoria de como melhor gerenciar seu negócio, fomentando o empreendedorismo desse setor.

- Boas Práticas Agrícolas, de igual maneira, uma parceria entre entidades como Emater, Senar, Prefeitura e Universidades poderia ofertar um programa que tratasse sobre sistema de cultivo orgânico, gestão de resíduos, rotação de culturas, segurança do trabalho e outros temas e orientaçôes técnicas que julgarem ser pertinentes para o aprimoramento da produção.

- Qualificação das feiras livres, uma ação que possa ser articulada entre diversas entidades, como Prefeitura, Sebrae, Emater, Senar e Universidades locais. A proposta é de instituir um programa que promova melhor organização e padronização das feiras, bem como, maior divulgaçáo das feiras pelas redes sociais, pelas mídias digitais e/ou impressas. Também, inserir as feiras livres nas pesquisas de preços de alimentos, visto que é um local onde se vendem produtos alimentícios; somado a isso, poderia proporcionar nas feiras, eventualmente, palestras e oficinas. Portanto, esse programa, espelhado nas informações contidas na cartilha "Parceria entre Consumidores e Produtores na Organização de Feiras", do Instituto Kairos, Badue e Gomes (2011), deverá constar açóes que estejam ancoradas nos seguintes eixos: infraestrutura, comunicação e formação.

As açóes supracitadas não têm caráter determinista, mas buscam ser caminhos que condicione a sustentabilidade dos empreendimentos, estendendo-se às feiras livres. Tais medidas visam valorizar e revitalizar as feiras, e em especial, proporcionar aos feirantes apoio e reconhecimento do seu trabalho e da agricultura familiar.

\section{REFERÊNCIAS}

AGÊNCIA DE DESENVOLVIMENTO DE SANTA MARIA - ADESM. Plano

Estratégico de Desenvolvimento de Santa Maria 2014 - 2030. 2013. Disponível em:<http://adesm.org.br/wpcontent/uploads/2013/10/Doc_Base_Plano_Estrategico_de_ Desenvolvimento_SM.29.10.pdf>. Acesso em: 22 maio 2016. 
ALBERGONI, L.; PELAEZ, V. Da Revolução Verde à agrobiotecnologia: ruptura ou continuidade de paradigmas? Revista de Economia, v. 33, n. 1 (ano 31), p. 31-53, jan./ jun. 2007.

ANDRADE, Edelaine Cristina de. Análise de uma proposta aplicada em sala de aula sobre geometria com foco na demonstração. 2011. 157 f. Dissertação (Mestrado em Ensino de Ciências e Educação Matemática) - Universidade Estadual de Londrina, Londrina, 2011.

ANGLADE, J. Agriculture durable et écologie: les indicateurs de durabilitè de la IDEA. Mèmorie de maîtrese de biologie dês organismes à L'Université d'Orsay (Paris-Sud XI), 1999.

AZEVEDO, F. F; QUEIROZ, T. A. N. As Feiras Livres e suas (Contra)Racionalidades: Periodização e Tendências a partir de Natal-RN-Brasil. Revista Bibliográfica de Geografía y Ciencias Sociales. vol. XVIII, no 1009, 2013.

BALSAN, R. Impactos Decorrentes da Modernização da Agricultura Brasileira. CampoTerritório: revista de geografia agrária, v. 1, n. 2, p. 123-151, ago. 2006.

BARBOSA, G. S. O Desafio do Desenvolvimento Sustentável. Revista Visóes. 4a ed., no 4, vol. 1, Jan./Jun., p. 1-11, 2008.

BRANDEMBURG, A. Do Rural Tradicional ao Rural Socioambiental. Revista Ambiente e Sociedade, v. XIII, no 2, p. 417-428, 2010.

BRASIL. Ministério da Saúde. Agência Nacional de Vigilância Sanitária (ANVISA).

Resoluçáo $\mathrm{RDC}^{\circ}$ 216, de 15 de setembro de 2004. Dispóe sobre Regulamento Técnico de Boas Práticas para Serviços de Alimentação. Disponível em: <www.anvisa.gov. br>. Acesso em: 10 nov. 2015.

BRASIL. Ministério do Meio Ambiente (MMA). Agenda 21. 1992. Disponível em: <http://www.mma.gov.br/responsabilidade-socioambiental/agenda-21/agenda-21-global>. Acesso em: 21 set. 2014.

CARNEIRO, M. J.; MALUF, R. S. Para além da produção: multifuncionalidade e agricultura familiar. Rio de Janeiro: MAUAD. 230p., 2003.

CARVALHO, T. Feiras livres da agricultura familiar. 2016. Disponível em: <http:// agrario.mg.gov.br/feiras-livres-da-agricultura-familiar/>. Acesso em: 09 jul. 2016.

DORNELES, J. L. B.; HILLESHEIM, L. P. O futuro do agricultor familiar na atividade leiteira no município de Entre-Ijuís/RS. In: Desenvolvimento rural e agricultura familiar: [recurso eletrônico]. Produção acadêmica da Ascar / organizado por Décio Cotrim. Porto Alegre, RS: Emater/RS-Ascar, 2014. 
FALEIRO, F. GLOBOECOLOGIA. Revolução Verde foi um programa de Expansão da Produtividade Agrícola. 2012. Disponível em: <http://redeglobo.globo.com/ globoecologia/noticia/2012/09/revolucao-verde-foi-um-programa-de-expansao-daprodutividade-agricola.html>. Acesso em: 27 ago. 2016.

FEIRAS livres resistem ao avanço das redes de supermercados. Jornal Zero Hora. Porto Alegre, 23 ago. 2008. Disponível em: <http://zh.clicrbs.com.br/rs/noticia/2008/08/feiraslivres-resistem-ao-avanco-das-redes-de-supermercados-2137072.html>. Acesso em: $10 \mathrm{abr}$. 2016.

FELIN, R. V.; MIORIN, V. M. F. Açóes em feiras livres do município de Santa Maria/ RS: O caso da feira da Rua Professor Teixeira. (Relatório de Pesquisa). Santa Maria: UFSM, 2006.

FUNDAÇÃO DE ECONOMIA E ESTATÍSTICA (FEE). Fundação de Economia e Estatística. Porto Alegre, 2015. Disponível em <www.fee.gov.br>. Acesso em: 11 jul. 2016.

GLIESSMAN, S. R. Agroecologia: processos ecológicos em agricultura sustentável. 2 ed. Porto Alegre: Ed. Universidade/UFRGS, 653p., 2001.

GONÇALVES NETO, W. Estado e Agricultura no Brasil, São Paulo: Hucitec, 1997. INSTITUTO BRASILEIRO DE GEOGRAFIA E ESTATÍSTICA - IBGE. Censo Agropecuário de 2006. Disponível em: www.sidra.ibge.gov.br. Acesso em: 29 ago. 2014.

INSTITUTO KAIRÓS; BADUE, A. F. B.; GOMES, F. F. F. Parceria entre Consumidores e Produtores na Organização de Feiras. São Paulo: Instituto Kairós, 2011.

KINJO, T.; IKEDA, A. A. Comportamento do consumidor em feiras livres. In: XLIII Congresso da SOBER - Sociedade Brasileira de Economia e Sociologia Rural. v. 1, 2005, Ribeirão Preto, SP. Anais... Ribeirão Preto: SOBER, 2005, p. 1-16.

LIMA, A. E. F.; SAMPAIO, J. L. F. Na feira a gente encontra de tudo...: aspectos da formação espacial da feira-livre de Abaiara? Ceará. In: V Simpósio Internacional de Geografia Agrária/ I Simpósio Nacional de Geografia Agrária, 2009, Niterói. Anais (Simpósio Nacional de Geografia Agrária ... Simpósio Internacional de Geografia Agrária. CD-Rom). Niterói: UFF, 2009.

MAROUELLI, Rodrigo P. O Desenvolvimento Sustentável da Agricultura no Cerrado Brasileiro. 2003. 55 f. Monografia (Especialização) - Curso em Gestão Sustentável, Fundação Getúlio Vargas, Brasília, 2003. 
MELO, L. E. L. de; CÂNDIDO, G. A. O Uso do Método IDEA na Avaliação de Sustentabilidade da Agricultura Familiar no Município de Ceará-Mirim - RN. REUNIR

- Revista de Administraçáo, Contabilidade e Sustentabilidade. vol.3, no 2, maio/ago., p. 1-19, 2013.

MENASCHE, Renata. Risco à Mesa: Alimentos Transgênicos, No Meu Prato Não?

Campos: Revista de Antropologia Social. Curitiba, v. 5, n.1, p. 111-129, 2004.

MENEZES, V. P. L. As feiras livres em Fortaleza - retrato da polissemia urbana. 2005. 130 f. Dissertação (Mestrado em Geografia) - Universidade Estadual do Ceará, Fortaleza, 2005.

MINNAERT, A. C. S. T. A feira livre sob um olhar etnográfico. In: Escritas e narrativas sobre alimentação e cultura. Organizado por Maria do Carmo Soares de Freitas, Gardênia Abreu Vieira Fontes e Nilce de Oliveira - Salvador: EDUFBA, 2008.

MORAES, R.; GALIAZZI, M. C. Análise Textual Discursiva. Ijuí: Ed. Unijuí, 224 p., 2007.

MOREIRA, R. J. Críticas Ambientalistas à Revolução Verde. 2000. Disponível em: <http://www.ufrrj.br/leptrans/5.pdf>. Acesso em: 22 set. 2014.

MOREL, A.P.S.; REZENDE, L.T.; SETTE, R. S. Negócio feira livre: análise e discussão sob a perspectiva do feirante. Revista Extensáo Rural, v. 22, p. 43-57, 2015.

MOTA, L. H. S.; CRUZ, D. R. C.; LIMA, J. S.; SANTANA, M. I. Práticas

Extensionistas: um Relato Experienciado na Feira Livre de Santo Antônio de Jesus - BA. 2012. Disponível em: <http://www3.ufrb.edu.br/ebecult/wp-content/uploads/2012/04/ Pra\%C3\%83\%C3\%85ticas-extensionistas-um-relato-experienciado-na-feira-livre-deSanto-A-nto\%C3\%83\%C3\%87nio-de-Jesus- $\%$ E2\%80\%9A\%C3\%84\%C3\%AC-BA-. pdf.>. Acesso em: 15 fev. 2016.

NANTES, J. F. D.; SCARPELLI, M. Elementos de gestão na produção rural. In: BATALHA, Mário Otávio (Coord.). Gestão agroindustrial. 3. ed. São Paulo: Atlas, p. 629-664, 2012.

NORA, F. D.; DUTRA, M. R. P. Etnografando feiras livres em praças de Santa MariaRS: as feiras ecológicas da Praça Saturnino de Brito e da Praça Saldanha Marinho. In: Somos todas mulheres iguais! Estudos antropológicos sobre feira, gênero e campesinato (E-book). São Leopoldo: Oikos, 2015.

NUNES, O. M; KARNOPP, E. Análise das Potencialidades Econômicas Endógenas no desenvolvimento do Município de Santa Maria/RS. Revista Gestáo e Desenvolvimento em Contexto. vol.1, no. 01, 2013. 
OLALDE, A. R. Agricultura familiar e desenvolvimento sustentável. 2004. Disponível em: <http://www.ceplac.gov.br/radar/Artigos/artigo3.htm.>. Acesso em: 27 set. 2016.

ORGANIZAÇÃO DAS NAÇÓES UNIDAS PARA A ALIMENTAÇÃO - FAO. World Food Day: Family Farming is the focus of World Food Day. 2014. Disponível em: <http://www.fao.org/world-food-day/home/en/>. Acesso em: 19 abr. 2015.

PECHE FILHO, A. Boas práticas ambientais na agricultura. 2015.

Disponível em: <http://www.diadecampo.com.br/zpublisher/materias/Materia. asp?id=31697\&secao=Artigos\%20Especiais $>$. Acesso em: 14 out. 2016.

PEREIRA FILHO, O. P. Implicaçóes ecológicas da utilizaçáo de energia em agroecossistemas. 1991. 132 f. Dissertação (Mestrado em Extensão Rural) - Universidade Federal de Santa Maria, Santa Maria, 1991.

PIERRI, M. C. P.; VALENTE, A. L. E. F. A feira livre como canal de comercializaçáo de produtos da agricultura familiar. In: XLVIII Congresso da SOBER, 2010, Campo Grande, MS. Disponível em: <http://www.sober.org.br/palestra/15/234.pdf>. Acesso em: 25 maio 2016.

PINTO, Moisés Augusto Tavares; MORAES, André de Oliveira. Espaço e economia: Crise e perspectivas no abastecimento em Manaus, Amazonas, Brasil. Revista Geográfica de América Central, Número Especial EGAL, 2011, p. 1-14.

PORTAL ONUBR. A ONU e o Meio Ambiente. Disponível em: <http://www.onu.org. br/a-onu-em-acao/a-onu-e-o-meio-ambiente/>. Acesso em: 18 set. 2014.

REIS, F.; VIEIRA, S. M. F. Tudo junto: pessoas, relações e peculiaridades na feira livre de Viçosa. In: Exposição de Pesquisa Experimental em Comunicação. 18., 2011, São Paulo. Anais..., São Paulo: Intercom, 2011.

SANTA MARIA (Município). Secretaria Municipal de Desenvolvimento Rural de Santa Maria - SMDR. Programa Rede de Desenvolvimento Rural. Folder. 2015.

SANTOS, J. G.; CÂNDIDO, G. A. A Sustentabilidade da Agricultura Orgânica Familiar dos Produtores Vinculados a Associaçáo de Desenvolvimento Econômico, Social e Comunitário (ADESC) de Lagoa Seca- PB. 2010.

SANTOS, G. R.; PIASENTIN, F. B. Estado e Desenvolvimento Rural no Brasil: contradições e desafios à sustentabilidade. Sociedade e Desenvolvimento Rural, v. 4, n. 3, p. 59-79, 2010.

SARTORI, S.; LATRONICO, F.; CAMPOS, L. M. S. Sustentabilidade e desenvolvimento sustentável: uma taxonomia no campo da literatura. Ambiente \& Sociedade. 2014, vol.17, n.1, pp.01-22. 
SILVA, Tiago Luís Coelho Vaz. Etnografando mercados: trabalho, sociabilidade e lazer no Ver-o-Peso. Somanlu, ano 11, n. 1, jan./jun. 2011.

SILVA, D. O.; CASTRO, J. R. B.; LOPES, K. P. S.; SILVA, A. O. Caracterização e Análise da Feira Livre de Cruz das Almas-BA sob a Ótica do Planejamento e Gestão Municipal. Caminhos de Geografia (UFU), v. 15, no 49, p. 1-13, 2014.

\section{SOCIEDADE NACIONAL DE AGRICULTURA (SNA). Mapeamento do MDS} identifica em torno de 64 mil feiras livres e agroecológicas em todo país. 2015. Disponível em: <http://sna.agr.br/mapeamento-do-mds-identifica-em-torno-de-64-milfeiras-livres-e-agroecologicas-em-todo-pais/>. Acesso em: 14 jul. 2016.

SOUZA, C. R. As feiras livres como lugares de produção cotidiana de saberes do trabalho e educação popular nas cidades: alguns horizontes teóricos e analíticos no campo Trabalho-Educação. Trabalho Necessário, v. 13, p. 1-19, 2015.

SOUZA, R. A. M. Nível de exigência do consumidor faz mudar a forma de distribuição de frutas e hortaliças. Revista Batata Show, no 15, ano 6, ago., 2006. Disponível em: <http://www.abbabatatabrasileira.com.br/revista15_019.htm>. Acesso em: 18 ago. 2016.

SUCESSÃO rural - saída pela educação. Correio do Povo, Porto Alegre, 04 nov. 2012.

TEIXEIRA, J.C. Modernização da Agricultura no Brasil: impactos econômicos, sociais e ambientais. 2005.

VEIGA, J. A face rural do desenvolvimento: natureza, território e agricultura. Porto Alegre: UFRGS, 2000. 